\title{
POTENCIAL EMPREENDEDOR: APLICAÇÃO DE ESCALA DE MENSURAÇÃO EM ALUNOS DE ENGENHARIAS
}

Rubens De Moura Leite ${ }^{1}$

Patricia Viveiros De Castro Krakauer ${ }^{1}$

${ }^{1}$ Centro Universitário Campo Limpo Paulista / Unifaccamp 


\section{POTENCIAL EMPREENDEDOR: APLICAÇÃO DE ESCALA DE MENSURAÇÃO EM ALUNOS DE ENGENHARIAS}

\section{Resumo:}

As empresas esperam receber das universidades jovens com comportamento empreendedor, que possam alavancar projetos e inovação. Assim, a educação empreendedora pode ser uma opção na composição da grade curricular de cursos, como, por exemplo, os de engenharia, objeto de estudo do presente artigo. De modo a estimular características comportamentais que favoreçam a formação como empreendedores, o potencial empreendedor passou a ser investigado nas instituições de ensino. Esta pesquisa busca investigar qual seja esse potencial nas engenharias, tendo dois objetivos: (i) analisar o potencial empreendedor dos estudantes universitários de engenharias e (ii) verificar o interesse dos discentes em atividades voltadas ao estímulo do empreendedorismo, apesar de não o fazem com frequência. Os resultados mostram que os alunos de engenharias possuem potencial para empreender e que têm o desejo de participar de atividades voltadas para o empreendedorismo. Acredita-se que este estudo poderá contribuir com instituições que queiram incluir empreendedorismo nas grades curriculares.

Palavras-chave: Educação empreendedora. Potencial empreendedor. Engenharias

\section{$1 \quad$ Introdução}

Em contextos competitivos, as empresas precisam recriar o cotidiano, procurando melhorar seu nível de eficiência e eficácia para atingir os melhores resultados. Por mais que a empresa tenha capacidade financeira para investir em seus ativos, é essencial ter ciência de que são as pessoas que farão uma relevante diferença nos seus resultados. Para isso, conforme menciona Hills, Seibert e Zhao (2005), as empresas esperam receber das universidades jovens com comportamento empreendedor, que possam alavancar projetos e inovação.

A educação empreendedora pode ser uma opção de prevalência na composição da grade curricular de diferentes cursos de graduação, nas Instituições de Ensino Superior (IES) brasileiras. Conforme estudo de Krakauer (2016), disciplinas de empreendedorismo que antes eram praxe na faculdade de administração, passa a estar presente em outras áreas do saber, como na odontologia, medicina, música e zootecnia.

As IES que investem na formação para o empreendedorismo possuem um importante diferencial ao seu favor, perante o mercado e estudantes, que buscam uma formação abrangente e de boa qualidade. Com isto, é possível afirmar que as Instituições de Ensino precisam investir em planejamento e treinamento de docentes para que possam ter pleno domínio de um conjunto razoável de técnicas, suas aplicações e possíveis adaptações, e também que se viabilize o estabelecimento de boas relações entre professores e alunos, fato que ganha importância no processo (LIBÂNEO, 1994; FREITAS; FREITAS, 2014).

Também é a realidade em cursos de engenharias, pois, segundo Rodrigues et al. (2006), o ensino do empreendedorismo se incorporou a diferentes cursos de engenharia e possibilitou 
a introdução de componentes curriculares que abordem o empreendedorismo nas grades curriculares de tais cursos, carecendo de desenvolvimento de atividades específicas e centros de empreendedorismo. Assim, segundo Gonçalves Filho et al. (2007) um passo seria o entendimento do potencial empreendedor dos estudantes da graduação de forma a poder estimular características comportamentais que favoreçam a formação como empreendedores.

Dado o contexto acima apresentado, esta pesquisa busca responder: qual o nível do potencial empreendedor dos estudantes de Engenharia? Pretendeu-se analisar esse nível através da escala de identificação do potencial empreendedor elaborada e validada no estudo de Santos (2008). Esse autor realizou um estudo voltado para a validação da escala que possibilita a comparação entre empreendedores de sucesso e a amostra que está sendo investigada. Na seção 3 a escala será apresentada com mais detalhes.

Esta pesquisa possui, então, dois objetivos: (i) analisar o potencial empreendedor dos estudantes universitários de engenharias e (ii) verificar o interesse dos discentes em atividades empreendedoras. Acredita-se que contribuirá com IES que queiram incluir empreendedorismo nas grades curriculares, desta forma, conhecer o potencial dos alunos pode favorecer a adequação de didáticas e planos de ensino voltados para essa área de aprendizagem, necessidade também mencionada na pesquisa de Krakauer (2016).

\section{$2 \quad$ Referencial Teórico}

Nessa seção são apresentados os fundamentos teóricos que alicerçaram a pesquisa de campo e a subsequente discussão de resultados, apresentada na seção 4.

\subsection{Educação Empreendedora}

O ensino do empreendedorismo tem como desafio resgatar os ideais da modernidade clássica, transformá-los e adaptá-los à modernidade radical, de ilimitadas possibilidades oferecidas pela criatividade, pela inovação. Somente com a modernização radical do campo educacional, que vai da pesquisa acadêmica às estratégias didáticas, poderá a escola desempenhar sua função social: formar o cidadão autônomo, com postura dinâmica e potencial criativo, utilizando conjuntamente a educação e a tecnologia disponível (NÓVOA, 1995).

Segundo Behrens (1999), o grande desafio é criar espaços verdadeiros nos quais o perfil do novo empreendedor ultrapasse o discurso e a retórica, provocando em contrapartida, ações efetivas e concretas no redimensionamento do seu papel, compatível com as exigências da realidade.

Imbernón (2002) ressalta que o ensino do empreendedorismo abrange um conhecimento pedagógico específico, a necessidade de dividir a responsabilidade com outros agentes sociais e um compromisso ético e moral. Quando se trata da aprendizagem dos alunos dos cursos de engenharia, principalmente nesse caso, a especificação da profissão está não somente no conhecimento pedagógico, mas, também na vivência cotidiana junto a esses alunos e na dinâmica experimentada em sala de aula, algo que se mostra como um desafio constante.

Fora isso, Imbernón (2002) menciona que em sendo um desafio, é preciso estabelecer um preparo que proporcione conhecimento válido e gere uma atitude interativa e dialética que 
possibilite valorizar a necessidade de uma constante atualização em face das transformações que se produzem.

Alguns são os modelos possíveis e discutidos na literatura para se ensinar empreendedorismo, como o de Krakauer, Serra e Almeida (2017), o de Rae (2005) e o modelo de Politis (2005). O primeiro é um modelo específico para o ensino do empreendedorismo na graduação, baseado na teoria da aprendizagem experiencial de Kolb (1984); o segundo se foca em três aspectos: formação pessoal/social, relação com o contexto e empreendimento negociável; e o terceiro que também considera a experiência como essencial para a aprendizagem empreendedora.

A partir de modelos voltados ao entendimento de como ensinar, propostas pedagógicas são mencionadas em estudos como possíveis para se ensinar empreendedorismo. Neck e Greene (2011) listam as que consideram adequadas à abordagem teórica processual, explorada no artigo das autoras: (i) aulas expositivas; (ii) empreendedores convidados; (iii) estudos de caso; (iv) elaboração de planos de negócios; (v) elaboração de modelos mentais; (vi) simulações; (vii) análise de oportunidades; (viii) realização de pesquisas; e (ix) estudo de narrativas.

Outro estudo que apresenta propostas pedagógicas para se ensinar empreendedorismo é o de Hashimoto, Krakauer e Cardoso (2018). Esses autores apresentam possibilidades de atividades experienciais para se ensinar empreendedorismo: (i) realização de um BootCamp composto de várias atividades em formato de jogos, como trilhas, atividade masterchef e paintball; (ii) improvisação teatral; (iii) desafios e realização de projetos; (iv) elaboração de modelo de negócios; e (v) apresentação de pitchs.

Krakauer (2014) pesquisou em sua tese de doutorado sobre as seguintes propostas: (i) estudo de casos; (ii) aulas dialogadas com problematização; (iii) elaboração de modelos de negócios; (iv) simulações; (v) jogos e desafios; (vi) discussão de exemplos; (vii) depoimentos de empreendedores; (viii) elaboração de plano de negócios; (ix) visitas a empresas; e (x) discussão de reportagens e de filmes.

Dessa forma, analisando as três pesquisas mencionadas acima, na presente dissertação serão inclusas no questionário as seguintes propostas, por estarem presentes ao menos em dois dos três trabalhos: (i) palestras com empreendedores convidados; (ii) realização de estudos de caso; (iii) elaboração de planos de negócios ou de modelos de negócios; (iv) simulações; e (v) jogos e desafios.

\subsection{Potencial Empreendedor}

Paquay et al. (2001) entendem que o potencial empreendedor dos alunos se refere ao conjunto formado por conhecimentos, o saber fazer e a postura perante os desafios, não descartando as ações e as atitudes necessárias ao exercício da profissão. Os autores consideram que essas potencialidades são de natureza cognitiva, conativa, afetiva e prática, além de estarem relacionadas às questões de natureza técnica e pedagógica na elaboração dos conteúdos. Tais potencialidades são também de natureza relacional, didática e social, que habilitam os estudantes a promoverem as interações em sala de aula. Saber fazer e a postura perante os desafios, não descartando aos atos atitudes indispensáveis ao desempenho da profissão. 
Para Tochon (2002) o potencial empreendedor está relacionado aos saberes estratégicos situados na interseção do cognitivo e do afetivo, ou de saberes pragmáticos, nos quais a vivência pessoal torna-se indissociável do conhecimento prático. Os saberes profissionais se desenvolvem também através da prática profissional, em campo, pela construção singular do sentido.

Complementando tais definições, observa-se no estudo de Alarcão et al. (1998) o entendimento de que o potencial empreendedor eficiente é aquele que apresenta as condições essenciais para que o desempenho profissional corresponda às expectativas orientadas pelo sistema educacional e pela sociedade.

O potencial empreendedor, de acordo com Longenecker, Moore e Petty (1997), vem cercado de forte necessidade e vontade de realização, autoconfiança e disposição em assumir riscos, em geral calculados. Para Schumpeter (1982), o potencial do empreendedor pode ser percebido naqueles indivíduos propensos a realização de mudanças, pouco conformados com rotinas profissionais. O empreendedor, é dotado de postura desafiadora e inovador, trabalha constantemente na criação de novas formas de organizar ou explorar novos recursos e materiais, desafia o mercado e a ordem econômica criando novos serviços ou produtos, inova processos.

O estudo de Santos (2008), que serve como guia para a atual pesquisa, tem por meta o entendimento dos elementos que definem o profissional ou sujeito potencialmente empreendedor. De acordo com o mesmo, os comportamentos estudados visam averiguar, por meio de uma escala, características comuns em amostra composta por indivíduos empreendedores frente à crença já convencionada de que a ação empreendedora não está relacionada unicamente à iniciação de novos negócios. Afirma-se, portanto, que a ação empreendedora está relacionada a traços particulares dos indivíduos, de ordem imaterial, associados à personalidade, atitudes, princípios, crenças, intenções, autoimagem, capacidade e modelos emocionais.

De acordo com Santos (2008) verificar e identificar o potencial empreendedor do indivíduo nos possibilita predizer com maior precisão se ele está propenso a ter sucesso em seus empreendimentos. $\mathrm{O}$ indivíduo que possui um significativo potencial empreendedor tende a ser mais resiliente na busca de atingir seus objetivos, aprende com seus erros e certos durante o processo de empreender.

Esse autor elaborou um quadro onde apresenta definições dos fatores da escala do potencial empreendedor (Quadro 1) que reflete as variáveis comportamentais somadas à intenção de empreender.

Especificamente sobre as engenharias, objeto de estudo da atual pesquisa, percebe-se que muitas são as possibilidades para o desenvolvimento do potencial empreendedor do engenheiro, uma vez que, segundo Castro et al. (2017) as universidades têm disciplinas que contribuem para formar profissionais aptos a atuarem em diferentes empresas ou gerenciarem o seu próprio negócio. Exemplificando essa realidade, esses autores afirmam que cerca de $58 \%$ da carga horária total do curso de engenharia de produção, de uma IES pública brasileira que investigaram, está direta ou indiretamente ligada à educação empreendedora, isto é, a matriz curricular em uso contribui para a promoção do potencial empreendedor e mesmo as disciplinas específicas voltadas à formação técnica contribuem em maior ou menor grau para a formação empreendedora. 
Quadro 1: Definições dos Fatores da Escala de Potencial Empreendedor

\begin{tabular}{|c|c|}
\hline Fator & Definição \\
\hline Oportunidade & $\begin{array}{l}\text { Mostrar que dispõe de senso de oportunidade, ou seja, está atento ao que aconte- } \\
\text { ce à sua volta e, a partir daí, ao identificar as necessidades das pessoas ou do } \\
\text { mercado, ser capaz de aproveitar situações incomuns para iniciar novas atividades } \\
\text { ou negócios. }\end{array}$ \\
\hline Persistência & $\begin{array}{l}\text { Capacidade de manter-se firme na busca do sucesso, demonstrando persistência } \\
\text { para alcançar seus objetivos e metas, superando obstáculos pelo caminho. Capaci- } \\
\text { dade de distinguir teimosia de persistência, admitir erros e saber redefinir metas e } \\
\text { estratégias. }\end{array}$ \\
\hline Eficiência & $\begin{array}{l}\text { Capacidade de fazer as coisas de maneira correta e, caso seja necessário, promo- } \\
\text { ver rapidamente mudanças para se adaptar às alterações ocorridas no ambiente. } \\
\text { Capacidade de encontrar e conseguir operacionalizar formas de fazer as coisas } \\
\text { melhor, mais rápidas e mais baratas. Capacidade de desenvolver ou utilizar proce- } \\
\text { dimentos para assegurar que o trabalho seja terminado a tempo. }\end{array}$ \\
\hline Metas & $\begin{array}{l}\text { Capacidade de mostrar determinação, senso de direção e de estabelecer objetivos } \\
\text { e metas, definindo de forma clara onde pretende chegar. Capacidade de definir } \\
\text { rumos e objetivos mensuráveis. }\end{array}$ \\
\hline Informações & $\begin{array}{l}\text { Disponibilidade para aprender e demonstrar sede de conhecimentos. Interesse em } \\
\text { encontrar novas informações em sua área de atuação ou mesmo fora dela. Estar } \\
\text { atento a todos os fatores internos e externos, relacionados à sua organização/em- } \\
\text { presa. Interesse em saber como fabricar produtos ou fornecer serviços. Disponibi- } \\
\text { lidade para buscar ajuda de especialistas em assuntos técnicos ou comerciais. }\end{array}$ \\
\hline Planejamento & $\begin{array}{l}\text { Disponibilidade para planejar suas atividades definindo objetivos. Capacidade de } \\
\text { planejar detalhando tarefas. Ser capaz de atuar com o planejamento, a execução e } \\
\text { o controle. }\end{array}$ \\
\hline Controle & $\begin{array}{l}\text { Capacidade de acompanhar a execução dos planos elaborados, manter registros e } \\
\text { utilizá-los no processo decisório, checar o alcance dos resultados obtidos. }\end{array}$ \\
\hline Persuasão & $\begin{array}{l}\text { Habilidade para influenciar pessoas quanto à execução de tarefas ou de ações que } \\
\text { viabilizem o alcance de seu objetivo. Capacidade de convencer e motivar pessoas, } \\
\text { liderar equipes e estimulá las usando as palavras e ações adequadas para influen- } \\
\text { ciar e persuadir. }\end{array}$ \\
\hline Rede de Relações & $\begin{array}{l}\text { Capacidade do indivíduo em estabelecer uma boa rede de relacionamentos com } \\
\text { conhecidos, amigos e pessoas que possam Ihe ser úteis, interessado em viabilizar } \\
\text { o alcance de seus objetivos. }\end{array}$ \\
\hline $\begin{array}{l}\text { Intenção de } \\
\text { Empreender }\end{array}$ & $\begin{array}{l}\text { Prenuncia a intenção de possuir, quer seja adquirindo de outrem ou partindo do } \\
\text { zero, um negócio próprio. }\end{array}$ \\
\hline
\end{tabular}

Fonte: Santos (2008), adaptado pelos autores 


\section{$3 \quad$ Método}

Trata-se de uma pesquisa de natureza descritiva, em que se busca destacar as características de população delimitada, fenômeno ou ainda determinar as associações entre as variáveis envolvidas (GIL, 2007). A abordagem da pesquisa é quantitativa e, de acordo com o pensamento de Fonseca (2002), os resultados da pesquisa quantitativa são passíveis de serem mensurados e retratam a realidade da população alvo do estudo.

Quanto ao método da pesquisa, será aplicado o levantamento de dados utilizando-se como meio de coletar os dados a escala desenvolvida e validada por Santos (2008). A escala foi idealizada para análise das comprovações de validade fatorial confirmatória, estrutura dimensional e validade de critério ou eficácia preditiva do potencial empreendedor. Santos (2008) alega que certos procedimentos psicométricos de validação mais exigentes para esta escala ainda não foram produzidos, como a validade fatorial confirmatória e de critério. Ele entende que a demonstração desses parâmetros pode fazer com que a utilização deste instrumento seja mais propagada e promover importantes contribuições ao empreendedorismo, de modo especial, vinculadas às pesquisas relacionadas ao potencial empreendedor.

Pesquisa realizada no Google Acadêmico em 11/03/2019 mostra que a tese que originou a escala de Santos (2008) foi citada 44 vezes e em vários desses trabalhos a escala foi utilizada, confirmando sua validação. Como exemplos: Araujo et al. (2016), Krakauer et al. (2018) e Souza et al. (2016).

Para desenvolvimento da pesquisa, os procedimentos de coletas de dados foram: (i) préteste do instrumento de pesquisa que foi realizado com três respondentes, com o intuito de verificar o nível de entendimento do respondente, eventuais dificuldades na interpretação das questões presentes na escala e o tempo para preenchimento; (ii) seleção dos indivíduos participantes da pesquisa: os entrevistados foram selecionados entre os estudantes de engenharias de ambos os sexos, para preencherem a escala pelo critério da acessibilidade, com amostra voluntária; e (iii) aplicação do questionário. Considerou-se que ao responder a pesquisa o respondente automaticamente autoriza a divulgação de suas respostas, sendo que isso foi explicado no cabeçalho do questionário.

Sobre o instrumento utilizado para a coleta de dados, foi utilizada a escala de Santos (2008). A escala tem o objetivo de identificar o potencial empreendedor e a intenção de empreender que um indivíduo possui por meio de características e traços de personalidade. Tais características são disponibilizadas na literatura e estão relacionadas ao perfil do empreendedor, tendo sido apresentadas no Quadro 1, na seção 2. A escala é composta por 49 itens no total, sendo 4 itens relacionados a intenção de empreender e 45 itens relacionados ao potencial empreendedor. Os itens podem ser classificados dentro de uma escala que vai de 0 (zero) a 10 (dez). Além dessas questões pertencentes a escala, foram inclusas outras, referentes ao perfil sociodemográfico da amostra e sobre as propostas pedagógicas mencionadas no item 2.1 da presente pesquisa.

Por questão de acessibilidade a pesquisa foi delimitada a região de Jundiaí (SP) e a amostra foi coletada em três IES que se dispuseram a colaborar, apesar do convite ter sido feito a dez Faculdades da região. Foi composta por 155 participantes, sendo que 123 estudantes universitários são do curso de engenharia de produção (EP) e 32 estudantes são do curso de engenharia mecânica (EM), que eram as engenharias presentes nas três instituições que 
aceitaram o convite. No entanto, foram encontrados dois outliers (estudantes que começaram a preencher o questionário e não o finalizaram) que, para maior confiabilidade da pesquisa, foram excluídos. Um era de EM e o outro de EP. Portanto, a contabilização final foi de 153 participantes, sendo 122 de EP e 31 de EM.

A diferença na quantidade de estudantes deu-se pela representatividade dos cursos nas instituições. No entanto, os resultados serão apresentados em valores normalizados e em porcentagens, de forma a permitir comparação diante da representatividade de cada curso.

Os dados foram analisados seguindo o preconizado por Santos (2008) no que se refere às questões da escala (Figura 1) e com estatística descritiva no que concerne perfil e propostas pedagógicas. E com relação ao escores foi considerado o preconizado por Santos, Minuzzi e Cruz (2010): escores até 2 indicam existência de potencial empreendedor e de intenção de empreender muito fracos; maiores de 2 até 4 fracos; maiores de 4 até 6 normais; maiores de 6 até 8 fortes; e maiores de 8 até 10 muito fortes.

\begin{tabular}{|c|c|c|c|}
\hline Cálculo da sua pontuação para Intenção de Empreendedor & Você & Empreendedores & $\begin{array}{c}\text { Você }+ \\
\text { Empreendedores }\end{array}$ \\
\hline Transfira e some os pontos obtidos nas questões: $\frac{\mathrm{v}_{1}}{+} \frac{\mathrm{v} 2}{\mathrm{v}}^{+} \frac{\mathrm{v} 3}{\mathrm{v}}^{+} \frac{\mathrm{v} 4}{\mathrm{v} 4}=1 / 4=$ & & 8,9 & \\
\hline \multicolumn{4}{|l|}{ Cálculo da sua pontuação para Intenção de Empreendedor } \\
\hline 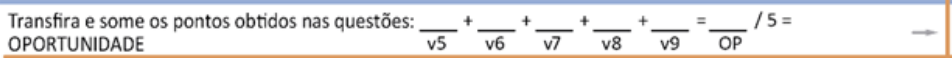 & & 8,1 & \\
\hline 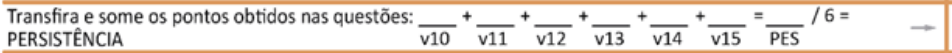 & & 8,9 & \\
\hline 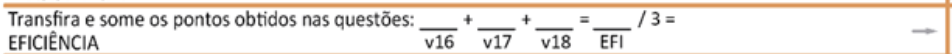 & & 9,1 & \\
\hline 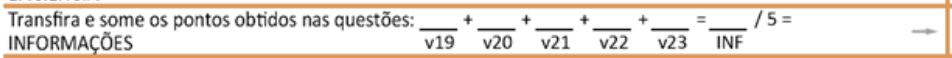 & & 9,0 & \\
\hline 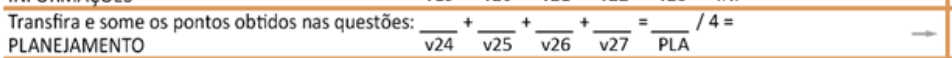 & & 8,2 & \\
\hline 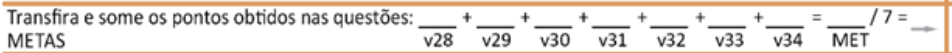 & & 8,5 & \\
\hline 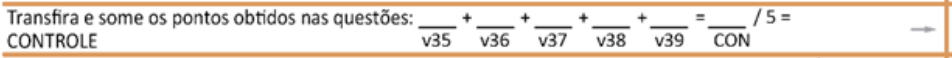 & & 8,3 & \\
\hline 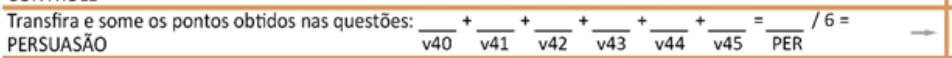 & & 8,4 & \\
\hline 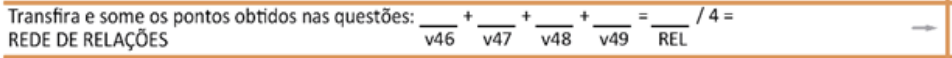 & & 8,6 & \\
\hline Obtenha seu potencial empreendedor: $\mathrm{PE}=(\mathrm{OP}+\mathrm{PES}+\mathrm{EFI}+\mathrm{INF}+\mathrm{PLA}+\mathrm{MET}+\mathrm{COM}+\mathrm{PER}+\mathrm{REL}) / 45=$ & & 8,6 & \\
\hline
\end{tabular}

Figura 1: Como se calcula o potencial empreendedor.

Fonte: Santos (2008)

\section{$4 \quad$ Resultados}

A amostra do presente artigo é composta por 79,7\% de estudantes do curso de Engenharia da Produção e 20,3\% por estudantes de Engenharia Mecânica. Do total da amostra de EP, 36\% são do sexo feminino e $64 \%$ são do sexo masculino, enquanto de EM, 3,2\% são do sexo feminino e $96,8 \%$ são do sexo masculino. Constatou-se que, analisando todos os respondentes juntos, a maioria dos participantes da pesquisa tem a idade de 22 a 25 anos, sendo de $40,5 \%$ da amostra; seguido de 38,5\% que compõe a idade de 18 a 21 anos e apenas $11,8 \%$ tem a idade de 26 a 30 anos, seguido da minoria, de 30 anos ou mais compondo 9,2\% da amostra. Foi possível verificar que em $52,3 \%$ da amostra total os pais possuem negócio próprio. Sendo que do curso 
de EP 51,6\% compõe esse dado e no de EM 54,8\% fazem parte desse cenário. Contudo, a relação não apresentou evidência estatística significativa para afirmar que estudantes que procuram o curso de EM ou EP sejam consequência de pais que possuem negócio próprio.

\subsection{Sobre atividades voltadas ao empreendedorismo}

Em sendo um dos objetivos verificar o interesse dos discentes em atividades empreendedoras, foi questionado aos alunos se já haviam participado das atividades elencadas a partir do referencial teórico e se teriam disposição em participar.

Sobre a participação (Tabela 1) levantou-se que entre os estudantes de EM, 54,8\% já participaram de palestras com empreendedores, $22,6 \%$ já realizaram estudos de caso, o mesmo percentual já elaborou plano ou modelo de negócios, 19,4\% responderam que já participaram de simulações e 48,4\% de jogos ou desafios. Em EP essa tendência se manteve, com 59,8\% já tendo participado de palestras, $36,1 \%$ já realizaram estudos de caso, 30,3\% já elaboraram plano ou modelo de negócios, $25,4 \%$ já realizaram simulações e 43,4\% de jogos ou desafios.

Embora, em números brutos, a quantidade de pessoas que participou seja maior em EP, é perceptível que o cenário, em proporções, encontra-se próximo ao da EM. Destaca-se que essas atividades já foram utilizadas e listadas em estudos anteriores como os de Neck e Greene (2011) e Hashimoto, Krakauer e Cardoso (2018), o que mostra que, na realidade das engenharias, há ainda a necessidade de um número maior de atividades que coloquem o estudante em contato direto com a realidade do empreendedorismo.

Sobre a disposição em participar das atividades voltadas ao estímulo do empreendedorismo (Tabela 1) percebeu-se que os percentuais são maiores do que quando se fala sobre a participação passada.

Tabela 1: Atividades voltados ao estímulo do empreendedorismo

\begin{tabular}{l|c|c|c|c}
\hline \multicolumn{1}{c|}{ Atividade } & \multicolumn{2}{c|}{ Engenharia Produção } & \multicolumn{2}{c}{ Engenharia Mecânica } \\
\hline & Participei & Tenho vontade & Participei & Tenho vontade \\
\hline Palestras com Empreendedores & $59,8 \%$ & $74,6 \%$ & $54,8 \%$ & $74,2 \%$ \\
\hline Realização de estudos de caso & $36,1 \%$ & $73,8 \%$ & $22,6 \%$ & $67,7 \%$ \\
\hline $\begin{array}{l}\text { Elaboração de plano ou modelo de } \\
\text { negócios }\end{array}$ & $30,3 \%$ & $78,7 \%$ & $22,6 \%$ & $74,2 \%$ \\
\hline Participação em simulações & $25,4 \%$ & $76,2 \%$ & $19,4 \%$ & $77,4 \%$ \\
\hline Participação em jogos ou desafios & $43,4 \%$ & $63,1 \%$ & $48,4 \%$ & $54,8 \%$ \\
\hline
\end{tabular}

(*): destaca-se a possibilidade de múltipla resposta no questionário

Fonte: elaborada pelos autores

Ao observar a Tabela 1 percebe-se que a atividade que alunos das duas engenharias menos gostariam de participar é jogos e desafios, mesmo assim, foi assinalada por mais da metade dos respondentes em ambos os casos.

Ao se confrontar as duas colunas - participei e tenho vontade - é possível perceber que, o interesse em participar são altos, demonstrando que há oportunidades para ofertas de atividades e treinamentos de empreendedorismo tanto aos alunos de EM, quanto aos alunos de EP, podendo-se inferir que ou a IES tem ofertado poucas atividades com esse teor ou há pouco 
estímulo para que o estudante participe, como divulgação da atividade ou mesmo estímulo direto dos docentes envolvidos.

\subsection{Sobre o potencial empreendedor dos alunos}

Para o outro objetivo da pesquisa, voltado a análise do potencial empreendedor dos estudantes universitários de engenharias, primeiramente foi analisado o constructo intenção de empreender (Tabela 2), de acordo com os escores preconizados por Santos, Minuzzi e Cruz (2010) e apresentado na seção de métodos.

Tabela 2: Intenção de empreender dos alunos das engenharias

\begin{tabular}{l|c|c|c|c|c}
\hline \multicolumn{1}{c|}{ Engenharias } & Muito forte & Forte & Normal & Fraco & Muito fraco \\
\hline Mecânica & $29,0 \%$ & $38,7 \%$ & $25,8 \%$ & $6,5 \%$ & $0,0 \%$ \\
\hline Produção & $41,8 \%$ & $27,9 \%$ & $23,8 \%$ & $4,9 \%$ & $1,6 \%$ \\
\hline Total & $39,2 \%$ & $30,0 \%$ & $24,2 \%$ & $5,2 \%$ & $1,4 \%$ \\
\hline
\end{tabular}

Fonte: elaborado pelos autores

Verificou-se que 60 estudantes de ambos os cursos possuem uma intenção muito forte, correspondendo a 39,2\% da amostra e que $30 \%$ possui forte intenção de empreender. Portanto, é possível afirmar que são cursos que possuem estudantes com alto perfil empreendedor em sua maioria.

Os demais constructos que compõe o de potencial empreendedor, objeto fim da análise proposta por Santos (2008) foram analisados na sequência e podem ser visualizados nas Tabelas 3 e 4. Além da estatística descritiva foi também calculado o alpha de cronbach para verificação da consistência interna do questionário, seguindo Landis e Koch (1977) que considera para os alfa que apareceram na presente pesquisa: entre 0,80 e 0,61 é substancial e maior do que 0,80 quase perfeito, sendo que apenas um constructo foi avaliado como moderado (vide Tabela 4).

Tabela 3: Constructos do potencial empreendedor dos alunos de EM

\begin{tabular}{l|c|c|c|c|c}
\hline \multicolumn{1}{c|}{ Constructo } & $\begin{array}{c}\text { Alfa de } \\
\text { cronbach }\end{array}$ & Média & Mediana & $\begin{array}{c}\text { Desvio } \\
\text { padrão }\end{array}$ & $\begin{array}{c}\text { Erro } \\
\text { padrão }\end{array}$ \\
\hline Intenção de empreender & 0,842 & 6,960 & 7,250 & 1,950 & 0,350 \\
\hline Identificação de oportunidades & 0,784 & 7,095 & 7,140 & 1,239 & 0,222 \\
\hline Persistência & 0,850 & 8,713 & 9,000 & 1,171 & 0,210 \\
\hline Busca de eficiência & 0,761 & 8,973 & 10,000 & 0,635 & 0,114 \\
\hline Aquisição de informações & 0,685 & 9,003 & 9,200 & 0,830 & 0,149 \\
\hline Prática de planejamento & 0,803 & 7,185 & 7,500 & 1,581 & 0,284 \\
\hline Estabelecimento de metas & 0,879 & 7,440 & 7,857 & 1,688 & 0,303 \\
\hline Práticas de controle & 0,819 & 7,042 & 6,800 & 1,772 & 0,318 \\
\hline Persuasão & 0,920 & 7,882 & 7,833 & 1,556 & 0,279 \\
\hline Rede de relacionamentos & 0,842 & 8,133 & 8,250 & 1,606 & 0,288 \\
\hline Potencial para empreender & 0,952 & 7,901 & 8,133 & 1,049 & 0,188 \\
\hline
\end{tabular}

Fonte: elaborado pelos autores

Na Tabela 3 é possível observar que a menor das habilidades que os mesmos possui tratase das práticas de controle, seguida pela identificação de oportunidade. A maior das habilidades para o perfil empreendedor que os alunos do curso de EM possuem tratam-se da aquisição de 
informações, seguida da busca de eficiência e persistência, características próprias e também muito treinadas nos estudantes de Engenharia, reforçadas pelos conhecimentos técnicos do curso.

Quando as médias são comparadas aos empreendedores de sucesso - proposta da escala de Santos (2008) conforme apresentada na seção de métodos - verificou-se que apenas no constructo aquisição de informações os estudantes de EM encontram-se acima. No entanto, quando comparamos a mediana - medida que separa a amostra ao meio, isto é, mesma quantidade de respondentes acima e abaixo do valor - é possível verificar que mais de $50 \%$ da amostra encontra-se acima da medida estabelecida no potencial empreendedor nos constructos de persistência e aquisição de informações.

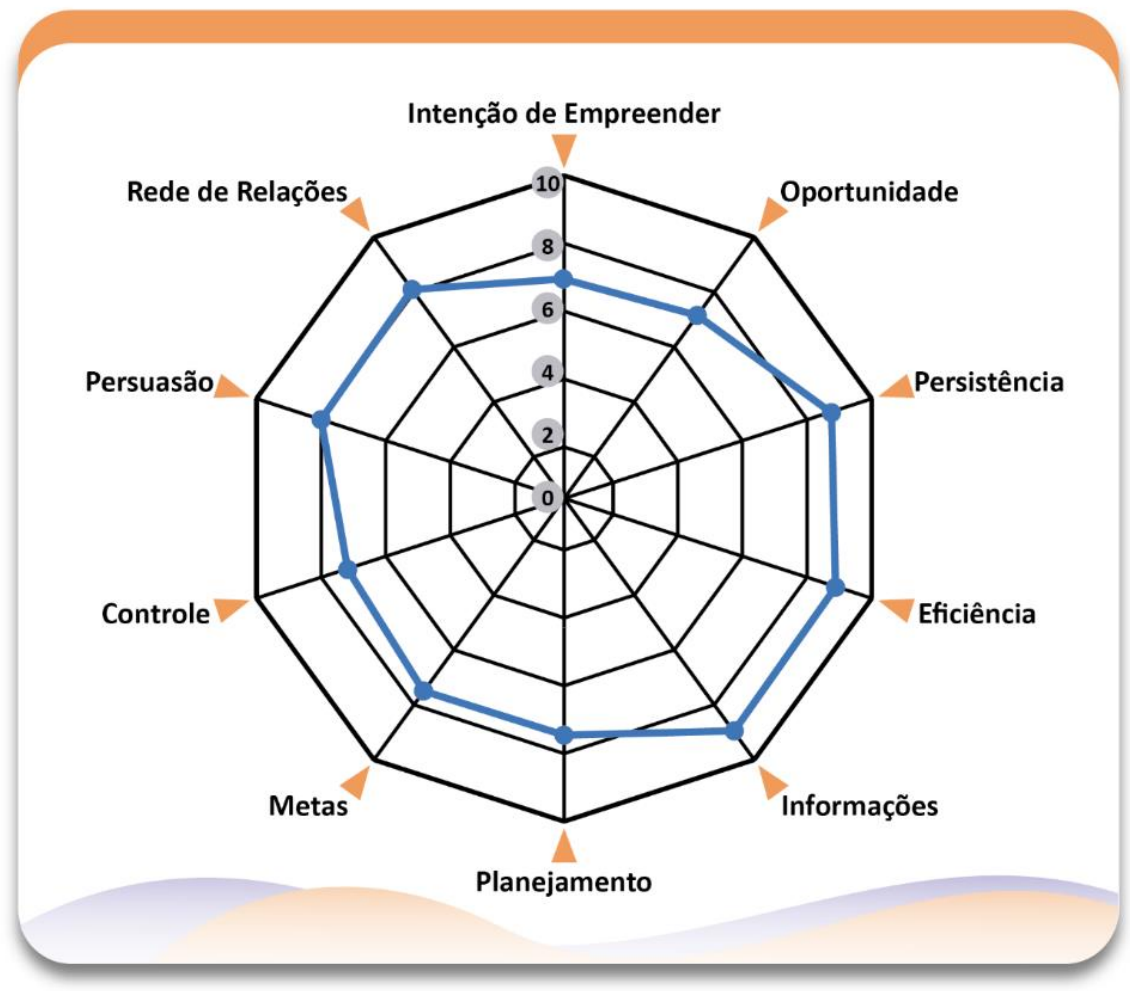

Figura 2: Gráfico radar do potencial empreendedor do curso de EM Fonte: elaborado pelos autores

A mesma analise foi realizada para os alunos de EP, como pode ser percebido na Tabela 4 e na Figura 3.

Tabela 4: Constructos do potencial empreendedor dos alunos de EP

\begin{tabular}{c|c|c|c|c|c}
\hline Constructo & $\begin{array}{c}\text { Alfa de } \\
\text { cronbarch }\end{array}$ & Média & Mediana & $\begin{array}{c}\text { Desvio } \\
\text { padrão }\end{array}$ & $\begin{array}{c}\text { Erro } \\
\text { padrão }\end{array}$ \\
\hline Intenção de empreender & 0,833 & 7,053 & 7,250 & 2,167 & 0,196 \\
\hline \hline
\end{tabular}




\begin{tabular}{l|c|c|c|c|c}
\hline Identificação de oportunidades & 0,767 & 7,582 & 7,600 & 1,410 & 0,128 \\
\hline Persistência & 0,810 & 8,785 & 8,833 & 0,958 & 0,087 \\
\hline Busca de eficiência & 0,591 & 9,113 & 10,000 & 0,967 & 0,088 \\
\hline Aquisição de informações & 0,678 & 9,034 & 9,200 & 0,821 & 0,074 \\
\hline Prática de planejamento & 0,826 & 7,227 & 7,375 & 1,783 & 0,161 \\
\hline Estabelecimento de metas & 0,884 & 7,900 & 8,000 & 1,418 & 0,128 \\
\hline Práticas de controle & 0,841 & 7,846 & 8,200 & 1,549 & 0,140 \\
\hline Persuasão & 0,876 & 8,120 & 8,333 & 1,338 & 0,121 \\
\hline Rede de relacionamentos & 0,839 & 8,414 & 8,750 & 1,438 & 0,130 \\
\hline Potencial para empreender & 0,935 & 8,217 & 8,222 & 0,874 & 0,079 \\
\hline
\end{tabular}

Fonte: elaborado pelos autores

As maiores habilidades dos alunos de EP referem-se à busca de eficiência e aquisição de informações. Quanto à segunda, como já tratado anteriormente, refere-se à uma habilidade muito importante à graduação das engenharias. Quanto à habilidade de busca de eficiência, trata-se de resultado do forte exercício que é proporcionado no curso, visto que o engenheiro de produção trabalha com aspectos como metas de produção, cálculos de eficiência e busca de maior produtividade. Portanto, trata-se de uma consequente habilidade pela formação do profissional dessa engenharia. essas habilidades são seguidas, respectivamente, por persistência, rede de relacionamentos e persuasão.

Ao comparar as medianas da amostra, o curso de EP possui valores acima dos índices estabelecidos nas habilidades de busca de eficiência - que apresentou uma mediana no valor máximo de 10 , isto é, mais de $50 \%$ da amostra possuem a máxima pontuação nessa habilidade - seguida pelos constructos aquisição de informação e redes de relacionamentos. Destaca-se que, segundo De Bem Noro (2012), o engenheiro de produção, em sua formação, é treinado a gerenciar projetos e, portanto, a habilidade rede de relacionamentos tem fundamental importância, pois o maior desafio de um gerente de projetos é construir um relacionamento positivo com as partes interessadas de seus projetos, garantindo o suporte um ambiente favorável à sua realização.

Ao se comparar com os empreendedores de sucesso, os constructos busca de eficiência, aquisição de informação e redes de relacionamentos superaram os índices de empreendedores de sucesso alcançados na pesquisa de Santos (2008). 


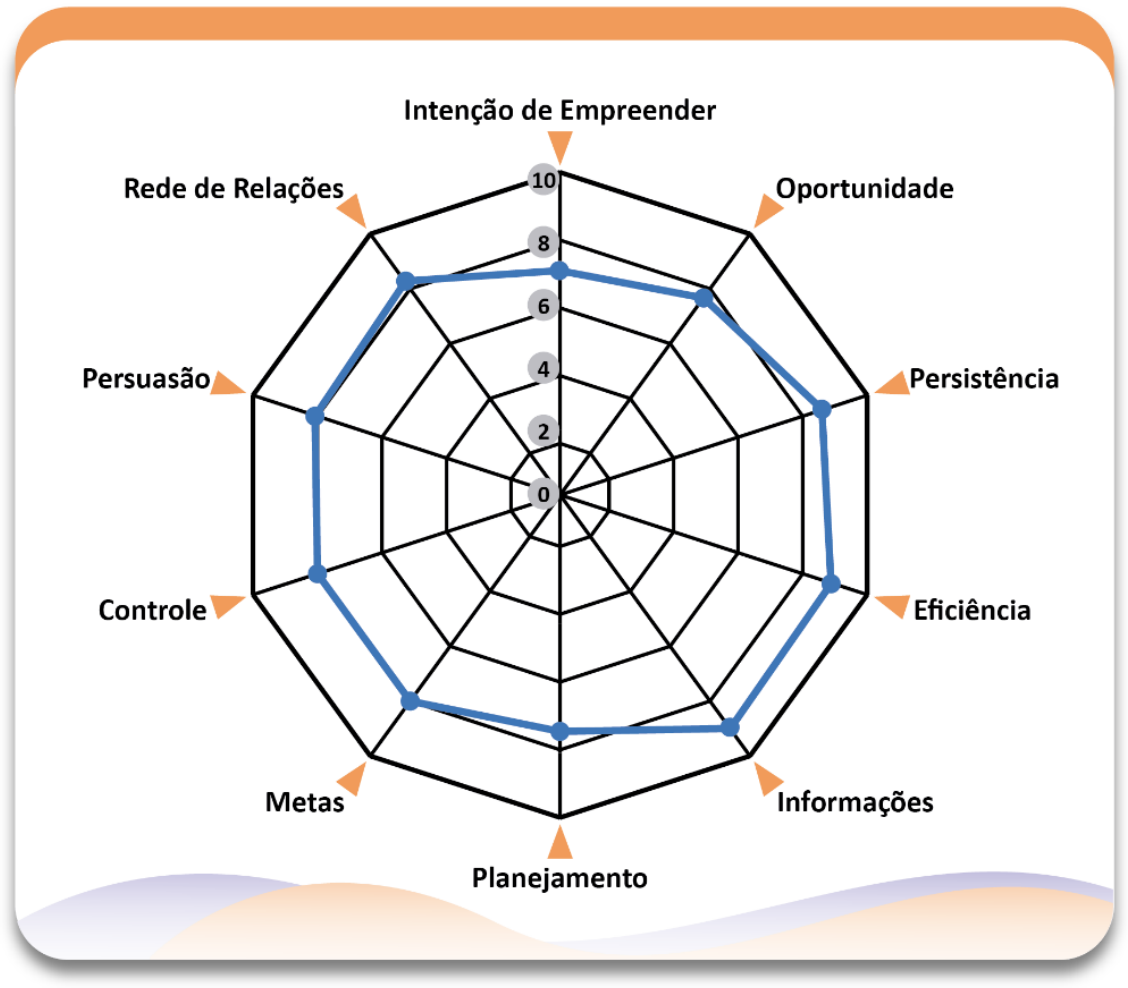

Figura 3: Gráfico radar do potencial empreendedor do curso de EP Fonte: elaborado pelos autores

De forma a responder o questionamento apresentado na seção introdutória, a saber, qual o nível do potencial empreendedor dos estudantes de Engenharia, foi analisada a amostra total desta pesquisa, como pode ser visualizada na Tabela 5.

Tabela 5: Constructos do potencial empreendedor de todas a amostra

\begin{tabular}{l|c|c|c|c|c}
\hline \multicolumn{1}{c|}{ Constructo } & $\begin{array}{c}\text { Alfa de } \\
\text { cronbach }\end{array}$ & Média & Mediana & $\begin{array}{c}\text { Desvio } \\
\text { padrão }\end{array}$ & $\begin{array}{c}\text { Erro } \\
\text { padrão }\end{array}$ \\
\hline Intenção de empreender & 0,833 & 7,034 & 7,250 & 2,119 & 0,170 \\
\hline Identificação de oportunidades & 0,774 & 7,483 & 7,600 & 1,387 & 0,111 \\
\hline Persistência & 0,819 & 8,770 & 8,917 & 1,001 & 0,080 \\
\hline Busca de eficiência & 0,624 & 9,085 & 10,000 & 0,909 & 0,073 \\
\hline Aquisição de informações & 0,675 & 9,028 & 9,200 & 0,820 & 0,066 \\
\hline Prática de planejamento & 0,822 & 7,218 & 7,500 & 1,739 & 0,140 \\
\hline Estabelecimento de metas & 0,884 & 7,900 & 8,000 & 1,418 & 0,114 \\
\hline Práticas de controle & 0,840 & 7,683 & 8,000 & 1,623 & 0,130 \\
\hline Persuasão & 0,887 & 8,072 & 8,167 & 1,383 & 0,111 \\
\hline Rede de relacionamentos & 0,840 & 8,357 & 8,500 & 1,472 & 0,118 \\
\hline Potencial para empreender & 0,940 & 8,153 & 8,200 & 0,918 & 0,074 \\
\hline
\end{tabular}

Fonte: elaborado pelos autores 
É possível observar que apenas três constructos (busca de eficiência, aquisição de informações e identificação de oportunidades) foram classificados de acordo com o cálculo do alfa de cronbach, como substanciais. Todos os demais constructos foram classificados como quase perfeitos. Isso demonstra a solidez da pesquisa e a consistência dos dados e resultados apresentados.

Foi possível identificar através das respostas dos alunos das três instituições participantes da pesquisa, que os alunos das engenharias possuem um alto potencial para empreender, sendo que os alunos de EP possuem um potencial maior que os de EM, com uma média de 8,217 e 7,901, respectivamente. Portanto, os estudantes de EP possuem potencial classificado como muito forte, enquanto os de EM ficaram no limiar entre forte e muito forte. Destaca-se que Castro et al. (2017) consideram, inclusive, que a grade curricular das engenharias possui diversas disciplinas que estimulam o pensamento empreendedor, o que corrobora com os achados na presente pesquisa.

Ao se comparar este resultado com os obtidos na pesquisa de Araújo et al. (2016) que utilizou a mesma escala na área educacional, percebe-se compatibilidade nos achados empíricos, a despeito desse autor ter investigado alunos de outra área do saber. A exceção foi o constructo intenção de empreender, que se mostrou mais forte entre os alunos de engenharias do que entre os da área biológica e humanidades, investigados por Araújo et al. (2016).

\section{Conclusão}

Os resultados do levantamento com os estudantes de EM e EP mostram dados e testes estatísticos que permitem vislumbrar que a maior parte dos alunos nesses cursos são do sexo masculino, estão concentrados entre as idades de 22 a 25 anos e apenas 52,3\% da amostra total possuem pais com negócio próprio, não apresentando evidência estatística significativa para afirmar que estudantes que procuram o curso de EM ou EP sejam consequência de pais que possuem negócio próprio.

Grande parte dos estudantes possuem interesse em vivências de empreendedorismo como palestras, realização de modelos e planos de negócios, desafios, mas não vivenciaram muitas dessas. Para tanto, as ementas e planos de aulas dos cursos de engenharia deveriam incorporar às suas disciplinas tais práticas, visto a relevância e importância do tema, bem como ser da vontade manifesta dos alunos. Deve-se analisar, naquelas instituições em que tais atividades já são propostas, se não está faltando o estímulo adequado à participação dos alunos, visto haver despontado na presente pesquisa uma dissonância entre o desejo de participar de tais atividades e a real participação dos alunos.

Foi também possível identificar que os alunos possuem potencial empreendedor e apresentam destaque em algumas habilidades com índices acima dos estabelecidos pelos empreendedores de sucesso: para os estudantes de EM as maiores habilidades são aquisição de informações, busca de eficiência e persistência; e, para os estudantes de EP, aquisição de informações, busca de eficiência, persistência, rede de relacionamentos e persuasão.

Algumas limitações foram percebidas ao se finalizar esta pesquisa: (i) a amostra foi limitada a dois cursos de engenharia e selecionada por acessibilidade; (ii) o número de 
respondentes foi limitado, não atingindo um total que pudesse garantir a generalização dos achados; e a amostra foi restrita a região de Jundiaí, o que pode trazer viés aos resultados.

Tais limitações geram possibilidade de pesquisa futura. Sugere-se que a amostra seja expandida para outras regiões e outras IES, de forma que seja ampliada e possa trazer resultados conclusivos e generalizáveis. Estudos qualitativos também são bem-vindos para compreender em profundidade os constructos que se destacaram quando feita a comparação com empreendedores de sucesso, buscando elucidar pontos que possam esclarecer se engenheiros possuem aptidões específicas que fizeram com que tais constructos se sobressaíssem.

\section{Referências}

ALARCÃO, I.; FREITAS, C. V. de; PONTE, J. P. da; ALARCÃO, J.; TAVARES, M.J.F. A formação de professores no Portugal de hoje. Documento de Trabalho do CRUP — Conselho de Reitores das Universidades Portuguesas. Disponível em: http://www.ensino.uevora.pt/ensinobasico/CRUP\%20forminicialqualidade\%20Janeiro\%2020 00.pdf. Acesso em: 22/05/2018.

ARAÚJO, S. C.; SILVA, M. G. M.; BAZAN, D. L.; SILVEIRA, F. F. Mensuração do potencial empreendedor de alunos de graduação em uma universidade pública. Anais do V SINGEP São Paulo - SP - Brasil - 20, 21 e 22/11/2016.

BEHRENS, M.A. O Paradigma Emergente e a Prática Pedagógica. Curitiba: Champagnat, 1999.

CASTRO, T. R.; FERNANDES, A. C.; JUNKES, V. H.; SILVA, V. L. O potencial empreendedor do curso de Engenharia de Produção: o caso da UNESPAR. XI encontro de engenharia de produção agroindustrial, 12 a 14 de dez, 2017.

DE BEM NORO, Greice. A gestão de stakeholders em gestão de projetos. Revista de Gestão e Projetos-GeP, v. 3, n. 1, p. 127-158, 2012.

FONSECA, J. J. S. Metodologia da pesquisa científica. Fortaleza: UEC, 2002. Apostila.

FREITAS, E.L. C.; FREITAS, A.A.F. Avaliação do Ensino de Empreendedorismo entre Estudantes Universitários por meio do Perfil Empreendedor. RAC, Rio de Janeiro, v. 18, n. 4, art. 5, pp. 465-486, Jul./Ago. 2014. Disponível em: www.anpad.org.br/rac. Acesso em julho 2018.

GIL, A., C. Como elaborar projetos de pesquisa. $4^{\circ}$ Ed. São Paulo: Atlas, 2007.

GONÇALVES FILHO, C.; VEIT, M. R.; GONÇALVES, C. A. Mensuração do Perfil do Potencial Empreendedor e seu impacto no desempenho das pequenas empresas. Revista de Negócios, v. 12, n. 3, p. 29-44, 2007. 
HASHIMOTO, M.; KRAKAUER, P. V. C.; CARDOSO, A. M. Inovações nas técnicas pedagógicas para a formação de empreendedores. Pensamento Contemporâneo em Administração, v. 12, n. 4, p. 17-38, 2018.

HILLS. G.E.;. SEIBERT, AS.E.; ZHAO, H., S. E The Mediating Role of Self-Efficacy in the Development of Entrepreneurial Intentions. The Journal of Applied Psychology 90(6), 12651272. SAEED, 2005.

IMBERNÓN, F. Formação Docente e profissional: formar-se para a mudança e a incerteza. 3 ed. São Paulo: Cortez, 2002.

KOLB, David A. Experiential learning: experience as the source of learning and development. New Jersey: Prentice Hall, 1984.

KRAKAUER, P. V. de C. Ensino de empreendedorismo: estudo exploratório sobre a aplicação da teoria experiencial. 2014. Tese (Doutorado em Administração) - Faculdade de Economia, Administração e Contabilidade, Universidade de São Paulo, São Paulo: USP, 2014.

KRAKAUER, P. V. de C. Empreendedorismo como disciplina: mapeamento das ideias fundamentais. Relatório de Pesquisa de Pós-Doutorado. Universidade de São Paulo, 2016.

KRAKAUER, P. V. de C.; SERRA, F. A. R.; ALMEIDA, M. I. R. Using experiential learning to teach entrepreneurship: a study with Brazilian undergraduate students, International Journal of Educational Management, Vol. 31 Issue: 7, pp.986-999, 2017.

KRAKAUER, P. V. C.; MORAES, G. H. S. Mo.; CODA, R.; BERNE, D. F. Brazilian women's entrepreneurial profile and intention. International Journal of Gender and Entrepreneurship, v.10, n.4, p. 361-380, 2018.

LIBÂNEO, J. C. Didática. 24 ed. São Paulo: Cortez, 2005.

LANDIS, J.R.; KOCH, G.G. The measurement of observer agreement for categorical data. Biometrics. Biometrics, v. 33, n.1, p. 159-174, 1977.

LONGENECKER, J, G; MOORE, C. W; PETTY, J. W. Administração de Pequenas Empresas: Ênfase na gerência empresarial. Tradução: ROSA, M. L. G. L. e STANCATTI, S. São Paulo: Makron Books, 1997.

NECK, H. M.; GREENE, P. G. Entrepreneurship education: Known worlds and new frontiers. Journal of Small Business Management, v. 49(1), p. 55-70, 2011.

NÓVOA, A. Os professores e sua formação. Lisboa: Dom Quixote, 1992. 
PAQUAY, L. PERRENOUD, P. ALTET, M. CHARLIER, E. (org.) Formando Professores Profissionais: Quais estratégias? Quais competências? 2a ed. Ver. Porto Alegre: Artmed Editora, 2001.

POLITIS, D. (2005), "The process of entrepreneurial learning: a conceptual framework", Entrepreneurship Theory and Practice, v. 29, n.4, pp. 399-424.

RAE, D. (2005), Entrepreneurial learning: a narrative-based conceptual model", Journal of Small Business and Enterprise Development, v. 12, n. 3, pp. 323-335.

RODRIGUES, E. F. ; NOGUEIRA, M. de S.; NÓBREGA, M. C. M.; PASCARELLA, R. Entrepreneurship and Engineering. Anais do International Conference of engineering Education , v. I, p. 19-21, 2006.

SANTOS, P. da C. F. dos. Uma escala para identificar potencial empreendedor. Tese (Doutorado) - Universidade Federal de Santa Catarina, Programa de Pós-Graduação em Engenharia de Produção, Florianópolis, 2008. Disponível em: https://repositorio.ufsc.br/bitstream/handle/123456789/91191/247610.pdf Acesso em j 20/05/2018.

SANTOS, PCF; MINUZZI, J.; CRUZ, NJT. Propensão e Potencial Empreendedor em Estudantes de Farmácia. EGEPE-Encontro de Estudos sobre Empreendedorismo e Gestão de Pequenas Empresas. Recife, Anais... Recife, 2010.

SCHUMPETER., J.A. Teoria do desenvolvimento econômico: uma investigação sobre lucros, capital, crédito, juro e o ciclo econômico. São Paulo: Abril Cultural, 1982.

SOUZA, G. H. S.; SANTOS, P. C. F.; LIMA, N. C.; CRUZ, N. J. T.; LEZANA, A. G. R. Entrepreneurial potential and success in business: a study on elements of convergence and explanation. RAM, REV. ADM. MACKENZIE, v.17, n.5, p. 188-215, 2016.

TOCHON, F. V. Tropics of teaching. Toronto: University of Toronto Press, 2002. 